\title{
The Effect of Practical Learning on Creative Thinking Skills of High School Students on Acid-Base
}

\section{*Sayid Zulkifli Sayid Alwi \& Suherman}

Pendidikan Kimia/FKIP - Universitas Tadulako, Palu - Indonesia 94119

Received 11 September 2020, Revised 19 October 2020, Accepted 16 November 2020

doi: 10.22487/j24775185.2020.v9.i4.pp213-218

\begin{abstract}
This study aims to determine the effect of practical learning on the creative thinking skills of class XI students on acid-base material at SMAN 7 Palu. This type of research was a quasi-experimental research with equivalent control group design. Sampling in this study was a purposive random sampling technique. The sample consisted of two classes students in XI MIA 2 as the experimental class $(n=24)$ and students in class XI MIA 4 as the control class $(n=24)$. Data from students' creative thinking using the one-party hypothesis testing, the right side were in this study used the statistics application and obtained sig. (2-tailed) 0,000 data based on this decision, the hypothesis is accepted if the sig (2-tailed) value is smaller than 0.05 so that it can be concluded that there is a positive effect using practical learning on the creative thinking ability of class XI students on acid-base material at SMAN 7 Palu.
\end{abstract}

Keywords: Practicum methods, creative thinking, acid-base

\section{Pendahuluan}

Metode praktikum atau eksperimen adalah metode pemberian kesempatan kepada siswa perorangan atau kelompok untuk dilatih melakukan suatu proses atau percobaan (Djamarah, 2006). Metode eksperimen dapat membuat anak didik lebih percaya atas kebenaran atau kesimpulan berdasarkan percobaannya sendiri daripada hanya menerima kata guru atau buku. Penggunaan metode eksperimen mempunyai tujuan agar siswa lebih percaya atas kebenaran berdasarkan percobaan sendiri dari pada hanya menerima kata guru atau buku saja (Pamungkas dkk., 2017).

Pembelajaran berbasis praktikum diarahkan pada experimental learning yakni pembelajaran dengan berdasarkan pada pengalaman konkret, diskusi dengan teman yang selanjutnya dapat diperoleh ide dan konsep baru. Belajar dipandang sebagai proses penyusunan pengetahuan dari pengalaman konkret, aktivitas kolaboratif dan refleksi serta interpretasi. Strategi pembelajaran yang berbasis praktikum dapat mendukung siswa untuk mengembangkan hands on dan minds on. Oleh karena itu, pembelajaran berbasis praktikum dapat digunakan sebagai alternatif pembelajaran yang dapat mendorong siswa belajar aktif untuk merekonstruksi pemahaman konseptualnya (Winarti, 2012).

Kreativitas dalam bidang pendidikan sains menjadi salah satu kebutuhan yang penting, terutama dalam konteks pembelajaran di sekolah seiring dengan perkembangan IPTEK saat ini (Sari dkk., 2016). Kreativitas berpikir siswa dapat ditingkatkan melalui proses pembelajaran, sedangkan kreativitas berpikir siswa dapat meningkatkan kemampuan berpikir serta kemampuan mengkonstruksi pengetahuan baru sebagai upaya meningkatkan penguasaan terhadap materi pelajaran (Segala, 2010). Meningkatkan keterampilan berpikir tingkat tinggi siswa, menggunakan kegiatan kreatif dalam pengajaran di kelas (Remirez \& Ganaden, 2008).

Berpikir kreatif penting dipupuk dan dikembangkan karena dengan berkreasi orang dapat mewujudkan dirinya. Pemikiran kreatif perlu dilatih karena mampu membuat anak lancar dan luwes (fleksibel) dalam berpikir, mampu melihat suatu masalah dari berbagai sudut pandang, dan mampu melahirkan banyak gagasan (Smarabawa, 2013).

Kemampuan berfikir kreatif adalah aspek penting untuk membuat dan menemukan ide untuk menyelesaikan masalah (Khoiriyah \& Husamah, 2018). kreativitas dihasilkan dari kecenderungan untuk berpikir dan berperilaku kreatif. Pandangan kreativitas yang muncul ini memberikan landasan yang jauh lebih kuat untuk membangun aplikasi pendidikan (Silver, 1997).

Penelitian Wechsler, dkk., (2012) yang bertujuan menganalisis dimensi gaya kreatif. Hasilnya adalah adanya konstribusi yang signifikan prestasi kreatif dari indeks kreativitas verbal dan gaya yang inovatif. Kreativitas menurut Al-Oweidi

๑) 2020 the Author(s) retain the copyright of this article. This article is published under the terms of the Creative Commons Attribution License 4.0, which permits unrestricted non-commercial use, distribution, and reproduction in any medium, provided the original work is properly cited. 
(2013) adalah serangkaian kemampuan mental yang diarahkan oleh keinginan yang kuat untuk menghasilkan ide, alternatif, atau kemungkinan yang digunakan untuk memecahkan masalah dan berkomunikasi dengan orang lain (Trianggono \& Yuanita, 2018).

Berpikir kreatif menggunakan dasar proses berpikir untuk mengembangkan dan menemukan ide atau hasil yang orisinil, estetis, konstruktif, yang berhubungan dengan pandangan, konsep, dan menekankan pada aspek berpikir intuitif dan rasional untuk menjelaskan masalah dengan perspektif asli pemikir (Suartika, 2013). Tujuan dari bepikir kreatif adalah untuk merangsang keingintahuan dan meningkatkan kemampuan berpikir divergen atau menghasilkan ide-ide yang baru (Dilla, dkk., 2018). Sedangkan menurut Munandar (1999). Pemikiran kreatif dibutuhkan dalam memecahkan masalah (Sohibi \& Siswanto, 2012). Sehingga berfikir kreatif sangat diperlukan oleh siswa untuk melatih ide-ide kreatif siswa dalam setiap pelajaran termasuk materi asam basa pada pelajaran kimia. Belajar dalam ilmu kimia menekankan pada pengalaman langsung (Assriyanto dkk., 2014). Berdasarkan hasil wawancara dengan Guru di SMA Negeri 7 Palu, kemampuan berpikir kreatf siswa masih kurang. Hal ini disebabkan karena kurangnya inovasi dalam pembelajaran dimana siswa merasa sulit belajar karena tak dapat melihatnya secara langsung sehingga terkesan hanya menghayalkan saja.

Tulisan ini dimaksudkan untuk mengaplikasikan pembelajaran kearah experimenta pada materi asam-basa terhadap kemampuan berpikir kreatif siswa.

\section{Metode}

Penelitian ini merupakan penelitian eksperimen dengan desain control group pre-test post-test. Desain penelitian yang menggunakan desain eksperimen ini mengukur kondisi awal siswa dengan pre-test kemudian mengukur perbedaan kondisi kelas setelah diberi perlakuan yang berbeda dengan post-test dengan sebelumnya memastikan kedua kelas homogen pada kondisi awal (Fathur, dkk., 2012).

Subjek pada penelitian ini adalah siswa kelas XI ipa 2 dan XI ipa 4 , yag mana kelas XI MIA 2 sebagai kelas eksperimen $(\mathrm{n}=24)$ dan kelas XI MIA 4 sebagai kelas Kontrol $(\mathrm{n}=24)$.

Jenis data yang digunakan pada penelitian ini yaitu data kontinum dimana data ini terdiri atas tiga macam yaitu data ordinal, interval dan data rasio yang sesuai pada penelitian ini, dan sarana untuk memperoleh data atau informasi untuk menjawab masalah, penelitian ini juga dikenal dengan studi kepustakaan.

Teknik pegumpulan data yang di gunakan dalam penelitian ini yaitu dengan melakukan tes, berfikir kreatif.

Instrumen yang digunakan pada penelitian ini yaitu tes kemampuan berfikir keatif siswa yang berjumlah 9 butir soal. Pengukuran kemampuan berfikir kreatif diambil dari indikator-indikator yang terdapat pada kriteria berfikir kreatif.

Data kemudian dihitung dan dinilai dengan memberikan skor. Setelah seluruh butir soal dan jawaban diberi skor, maka langkah selanjutnya menghitung persentase skor jawaban dari setiap item atau butir soal dengan mengunakan rumus sebagai berikut:

$$
\text { Jawaban }=\frac{\text { skormentahyangdiperoleh }}{\text { skormaksimumideal }} \boldsymbol{x} 100 \%
$$

Setelah menghitung presentasi skor jawwaban dari tiap butir soal, selanjutnya menghitung presentase skor jawaban berdasarkan indikator masing masing soal tes berfikir kreatif disajikan pada Tabel 1 (Astuti, 2014).

Tabel 1 Kriteria penilaian hasil tes berfikir kreatif

\begin{tabular}{ll}
\hline Presentase jawaban & Kriteria penilaian \\
\hline $81-100$ & Sangat kreatif \\
$61-80$ & kreatif \\
$41-60$ & Cukup kreatif \\
$21-40$ & Kurang kreatif \\
$00-20$ & Tidak kreatif \\
\hline
\end{tabular}

Sebelum dilakukan pengujian hipotesis dengan mengunakan uji-t terlebih dahulu diadakan pengujian persyaratan analisis yaitu: Pengujian normalitas dilakukan untuk memeriksa apakah sampel yang diambil mempunyai kesesuaian dengan popolusi. Pengujian ini dilakukan dengan mengunakan uji Chi-Kuadrat $\left(\chi^{2}\right)$ (Purwanto, 2011). Uji homogenitas dilakukan untuk mengetahui kesamaan antar dua keadaan atau populasi. Uji homogenitas dengan melihat keadaan ke homogenan populasi, uji homegenitas yang dilakukan adalah uji fisher, (Riduwan, 2009). Untuk melihat seberapa jauh kebenaran hipotesisi yang telah dirumuskan didukung oleh data yang dikumpulkan, maka hipotesis tersebut harus di uji. Pengujian kebenaran hipotesis dilakukan dengan mengunakan teknik statistik adapun hipotesisinya sebagai berikut

$\mathrm{H}_{0}=\mu 1 \leq \mu 2$ :

Kereatifitas berfikir siswa kelas XI SMAN 7 Palu pada materi asam basa dengan mengunakan metode pembelajaran praktikum adalah lebih rendah atau sama dengan kreatifitas berfikir siswa yang tampa mengunakan metode pembelajaran praktikum.

$\mathrm{H}_{1}=\mu 1>\mu 2$ : 
Kreatifitas berfikir siswa kelas XI SMAN 7

Palu pada materi asam basa dengan mengunakan metode pembelajaran praktikum adalah lebih tinggi dari kreatifitas berfikir siswa yang tampa mengunakan metode pembelajaran praktikum.

Untuk menentukan kretifitas berfikir siswa kelas XI pada materi asam basa di SMAN 7 Palu, digunakan uji statistik, yaitu uji-t satu pihak (Sudjana, 2002).

\section{Hasil dan Pembahasan}

\section{Deskripsi data hasil penelitian}

Hasil perhitungan nilai rata-rata dan nilai standar deviasi tes berfikir kreatif kimia siswa kelas XI pada materi Asam-Basa SMAN 7 Palu antara siswa yang mengikuti metode pembelajaran praktikum dan yang tidak mengikuti metode pembelajaran praktikum disajikan pada Tabel 2 .

Tabel 2 Analisis hasil tes berfikir kreatif kelas eksperimen dan kelas kontrol

\begin{tabular}{lll}
\hline \multirow{2}{*}{ Sampel Nilai } & \multicolumn{2}{c}{ Tes Berfikir Kreatif } \\
\cline { 2 - 3 } & Kelas Eksperimen & Kelas Kontrol \\
\cline { 2 - 3 } & Skor & Skor \\
\hline Sampel & 24 & 24 \\
Skor Minimum & 55 & 33 \\
Skor Maksimum & 95 & 84 \\
Nilai Rata-Rata & 75,70 & 47,37 \\
Standar deviasi & 10,49 & 11,96 \\
\hline
\end{tabular}

Selanjutnya hasil berfikir kreatif siswa pada

kreatif sampai dengan tidak kreatif disajikan pada Tabel 2 dikelompokkaan dalam kategori sangat Tabel 3.

Tabel 3. Kriteria penilaian dan frekuensi berfikir kreatif siswa

\begin{tabular}{llll}
\hline \multirow{2}{*}{ Nilai } & \multirow{2}{*}{ Kriteria Penilaian } & \multicolumn{2}{c}{ Frekuensi } \\
\cline { 3 - 4 } & & Kelas Eksperimen & Kelas Kontrol \\
\hline $81-100$ & Sangat Kreatif & 8 & 1 \\
$61-80$ & Kreatif & 15 & 2 \\
$41-60$ & Cukup Kreatif & 1 & 13 \\
$21-40$ & Kurang Kreatif & 0 & 8 \\
$00-20$ & Tidak Kreatif & 0 & 0 \\
Jumlah & & 24 & 24 \\
\hline
\end{tabular}

Dari Tabel 3 di atas dapat memperlihatkan bahwa berdasarkan nilai tes berfikir kreatif yang diajar mengunakan metode praktikum, tergolong sangat kreatif pelajaran kimia materi Asam-Basa sebanyak 8 orang dengan persentase sebanyak $33 \%$, yang tergolong kreatif sebanyak 15 orang atau $63 \%$, yang tergolong cukup kreatif sebanyak 1 orang dengan persentase $4 \%$ dan kategori kurang kreatif dan kreatif sebanyak 0 siswa dengan persentase sebanyak $0 \%$. Sedangkan nilai tes berfikir kreatif yang diajar tampa mengunakan metode praktikum yang tergolong sangat kreatif sebanayak 1 orang dengan persentase $4 \%$, yang tergolong kreatif sebanyak 2 orang dengan persentase $8 \%$, cukup kreatif sebanyak 13 orang dengan persentase 54\%, kurang kreatif sebanyak 8 orang dengan persentase $34 \%$ dan yang tidak kreatif sebanyak 0 siswa dengan persentase $0 \%$. Ini menunjukkan bahwa siswa yang diajar dengan mengunakan metode praktikum lebih baik dibandingkan dengan tampa mengunakan metode praktikum.

\section{Pengujian Normalitas dan Homogenitas}

Pada penelitian ini dilakukan uji chi-square untuk melihat apakah data berdistribusi normal atau tidak. Pengujian normalitas dan homogenitas merupakan uji prasyarat untuk statististik uji $t$ dalam hal ini digunakan uji satu pihak. Berdasarkan uji normalitas data tes berfikir kreatif mengunakan aplikasi spss diperoleh data nilai asymp.sig < nilai taraf signifikan $(\alpha)$. nilai asymp.sig. sebesar 0,026 sedangkan taraf signifikansi 0,05 sehingga dapat ditarik kesimpulan bahwa data tersebut berdistribusi normal.

Berdasarkan uji homogenitas data tes hasil berfikir kreatif belajar dalam penelitian ini digunakan aplikasi statistik yang mana dasar pengambilan keputusan didasari oleh nilai sig $>$ nilai taraf signifikan $(\alpha)$ yang mana diperoleh nilai sig. 0,654 dengan taraf signifikan sebesar 0,05 . Sehingga 
dapat disimpulkan bahwa data tersebut bersifat homogen. sehingga, data dapat diuji dengan mengunakan statistik uji t satu pihak.

\section{Pengujian Hipotesis}

Langkah terakhir dari pengujian prasyarat yaitu pengujian hipotesis dengan mengunakan uji t pihak kanan Berdasarkan hasil pengujian hipotesis dengan statistik uji satu pihak dimana pada penelitian ini bertujuan untuk melihat kreatifitas berfikir siswa dengan mengunakan metode pembelajaran praktikum. Berdasarkan pengambilan keputusan mengunakan aplikasi spss dilihat dari nilai sig (2 tailed) < nilai taraf signifikan $(\alpha)$ maka $\mathrm{H}_{1}$ yang diterima dan $\mathrm{H}_{0}$ ditolak mana diperoleh bahwa nilai sig (2 tailed) sebesar 0,00 dengan taraf signifikansi sebesar 0,05 sehingga diperoleh keimpulan bahwa terdapat pengaruh positif pembelajaran praktikum terhadap kreatifitas berfikir siswa pada materi Asam-Basa di SMAN 7 Palu. Hal ini sejalan dengan yang dikatakan Dryden dkk (2000). yang mengatakan alasan penting mengunakan pembelajaran praktikum adalah: $10 \%$ dari apa yang kita baca; 20\% dari apa yang kita dengar; 30\% dari apa yang kita lihat; 50\% dari apa yang kita lihat dan dengar; 70\% dari apa yang kita katakana; dan $90 \%$ dari apa yang kita lakukan.

Adanya perbedaan dari hasil berfikir kreatif siswa pada kelas eksperimen dan kelas kontrol ini dapat terjadi karna pembelajaran dengan metode pembelajaran praktikum dapat meningkatkan kreatifitas siswa dalam proses pembelajaran karna siswa dapat melakukan dan membuktikan sendiri teori yang ada sehingga mempermudah siswa dalam memamahami materi pembelajaran yang mana siswa tidak hanya sebatas membayangkan namunjuga dapat melihanya secara langsung

Pada pembelajaran dengan metode praktikum siswa dituntut untuk meningkatkan ketelitian keuletan dan ketabahan walaupun terkadang setiap percobaan tidak selalu memberikan hasil yang diinginkan. Adanya diskusi kelompok dan pengajuan hipotesis akan mengajak siswa untuk lebih membangun konsep bersama secara koopratif serta dapat melatih kemampuan berkomunikasi siswa. Siswandi (2006) menyatakan bahwa kemampuan berkomunikasi dapat meningkatkan kemampuan berpikir, bernalar dan kemampuan memperluas wawasan kemampuan untuk memanggapi persoalan disekitar siswa. Pembelajaran dengan metode praktikum juga memerlukan banyak fasilitas peralatan yang mana harus disediakan oleh peneliti. Hal ini harus diperhatikan oleh peneliti agar dapat memperlancar dan mengefektifkan pembelejaran dengan mealukan secara langsung melakukan secara langsung.

Metode pembelajaraan praktikum dalam penelitian ini mengukur kreatifitas berfikir dengan tiga indikator yaitu berfikir flexibelity, berfikir original dan berfikir fleuncy dimana berfikir fluency menekankan siswa untuk dapat mencetuskan banyak gagasan, dan jawaban penyelesaiaan sekaligus mampu memberikan lebih dari satu jawaban. Berfikir original juga menekankan siswa agar dapaat melahirkan ungkapan baru dan unik, dapat memikirkan cara-cara tak lazim untuk mengungkapkan diri dan mampu membuat kombinasi-kombinasi yang tak lazim dari bagianbagian atau unsur-unsur. Sedangkan berfikir flexibelity menekankan siswa agar dapat memberikan gagasan jawaban atau pertanyaan yang berfariasi, dapat melihat masalah dari sudat pandang yang berbeda dan mampu mengubah cara pendekatan atau pemikiran. Semakin sering siswa dilatih berpikir kritis dan kreatif secara ilmiah, akan semakin berkembang menjadi tidak hanya pemikir kritis dan kreatif tetapi juga sebagai pemecah masalah yang ada di lingkungannya (Lutfi, 2017).

Penelitian ini secara garis besar meliputi 3 tahap yaitu tahap persiapan , tahap pelaksanaan dan tahap pengolah data. Pada tahap pertama yaitu tahap persiapan peneliti mencoba mencari referensi yang sesuai dengan judul penelitian ini dan melakukan studi kepustakaan untuk memperdalam pengetahuan penliti tentang penelitian ini. Tahap kedua yaitu tahap pelaksanaan pada tahap ini peneliti pada awalnya melakukan pre test kepada siswa baik dikelas kontrol maupun kelas eksperimen ini digunakan guna mengukur kemampuan awal siswa dalam berfikir kreatif selanjutnya pada tahap pembelajaran dimana pada kelas kontrol digunakan pembelajaran inquiri tanpa metode praktikum sedangkan pada kelas eksperimen mengunakan metode praktikum. Tahap terakhir dalam penelitian ini yaitu tahap pengumpulan data dimana pada tahap ini diketahui bahwa nilai rata-rata siswa kelas kontrol sebanyak 47,37 lebih rendah jika dibandingkan dengan nilai rata-rata dari kelas eksperimen yang berjumlah 75,70 dan memiliki standar deviasi 10,49 sedangkan kelas kontrol memiliki standar deviasi 11,96 . 
Hasil pengujian hipotesis menunjukan bahwa terdapat perbedaan yang signifikan antara hasil berfikir kreatif siswa kelas kontrol dan kelas eksperimen dimana terdapat pengaruh positif pada pembelajaran praktikum terhadap kemampuan berfikir kreatifi siswa kelas XI pada materi AsamBasa di SMAN 7 Palu.

Hal-hal yang harus diperhatikan dalam pembelajaran dengan metode praktikum yaitu guru harus bisa membuat pembelajaran yang menyenangkan sehingga siswa siswa lebih efektif dan efisien dalam belajar. Adanya metode yang bervariasi tersebut dapat mengakomodasi berbagai karakteristik siswa sehingga membawa pengaruh positif dalam meningkatkan kreatifitas berfikir.

\section{Kesimpulan}

Nilai siswa pada kelas ekperimen dan kelas kontrol mengalami peningkatan setelah dan sebelum pembelajaran dibuktikan dari nilai pre test dan post test siswa namun jika dibandingkan dari kedua kelas maka kreatifitas berfikir siswa lebih baik pada kelas eksperimen dibandingkan kelas kontrol yang mana dibuktikan dengan nilai rata-rat kelas kontrol hanya 47,3708 sedangan nilai rata-rata kelas eksperimen yaitu 75,7083 sehingga diperoleh kesimpulan bahwa terdapat pengaruh positif pada pembelajaran praktikum.

\section{Ucapan Terima Kasih}

Ucapan terimaksih diucapkan kepada semua yang telah membantu penulis.

\section{Referensi}

Ajwar, M., Prayitno, B. A., \& Sunarno, W. (2015). Pengaruh pembelajaran inkuiri terbimbing dan inkuiri bebas termodifikasi terhadap prestasi belajar ditinjau dari berpikir kritis dan kedisiplinan belajar siswa kelas X MIA SMA Negeri 8 Surakarta tahun pelajaran 2014/2015. Jurnal Inkuiri, 4(3), 127-135.

Akcay, B. (2009). Problem based learning in science education. Journal of Turkish Science Education, 6(1), 26-36.

Arends, R. I. (2008). Learning to teach eighth edition. New York: Mc Graw Hill.

Arikunto, S. (2012). Dasar-dasar evaluasi pendidikan. Jakarta: Bumi Aksara.

Ayu, R., Nurrahmawati., \& Deswita, H. (2016). Pengaruh model pembelajaran problem based learning $(\mathrm{pbl})$ terhadap kemampuan pemecahan masalah matematika pada siswa kelas VII SMPN 3 Rambah Samo. Jurnal Mahasiswa Prodi Matematika, 2(2), 1-3.

Al-Oweidi, A. (2013). Creative characteristics and its relation to achievement and school type among jordanian students. Journal Creativity Education, 4(1), 29-34
Assriyanto, E. K., Sukardijo, S. J., \& Saputro, S. (2014). Pengaruh model pembelajaran berbasis masalah melalui metode eksperimen dan inkuiri terbimbing ditinjau dari kreativitas siswa pada materi larutan penjangga di sman 2 sukoharjo tahun ajaran 2013/2014. Jurnal Pendidikan Kimia, 3(3), 89-97.

Astuti, W. (2014). Pemanfaatan multimedia interaktif dalam pembelajaran matematikauntuk meningkatkan kemampuan berfikir kritis da kreatif siswa sekolah dasar. Thesis Tidak Diterbitkan. Bandung: Universitas pendidikan indonesia.

Dilla, S. C., Hidayat, W., \& Rohaeti, E. E. (2017). Faktor gender dan resiliensi dalam pencapaian kemampuan berpikir kreatif matematis siswa sma. Journal of Medivies, 2(1), 129-136.

Dryden, G. Jean., \& Nettervous., (2000). Revolusi cara belajar. Bandung: Kaifa.

Djamarah, S. B. (2006). Prestasi belajar dan kompetensi guru. Surabaya: Universitas Negeri Surabaya Press.

Khoiriyah, A. J., \& Husamah, H. (2018). Problembased learning: Creative thinking skills, problem-solving skills, and learning outcome of seventh grade students. Jurnal Pendidikan Biologi Indonesia, 4(2), 151-160.

Lutfi, A. (2013). Pengembangan media laboratorium virtual bersarana komputer untuk melatih berpikir kritis pada pembelajaran asam, basa, dan garam. Jurnal Penelitian Pendidikan Matematika dan Sains, 1(1), 27-33.

Pamungkas, H. S. M., Mulyani, S., \& Saputro, S. (2017). Penerapan model pembelajaran poe dengan metode praktikum untuk meningkatkan rasa ingin tahu prestasi belajar kimia siswa. Jurnal Penelitian Pendidikan, 20(1), 46-60.

Purwanto (2013). Evaluasi hasil belajar. Yokyakarta: Pustaka Jaya.

Remirez, R., \& Ganaden, M. (2008). Creative activities and students' higher order thinking skills. Journal Education Quarterly, 66(1), 2233.

Riduwan (2009). Belajar mudah penelitian untuk guru-karyawan dan peneliti pemula. Bandung: Alfabeta. 
Rohim, F., \& Susanto, H. (2012). Penerapan model discovery terbimbing pada pembelajaran fisika untuk meningkatkan kemampuan berpikir kreatif. UPEJ (Unnes Physics Education Journal), 1(1), 1-5.

Sari, W. P., Hidayat, A., \& Kusairi, S. (2016). Analisis keterampilan berpikir kreatif siswa SMA pada materi fluida statis. Jurnal Prosiding, 1(5), 307-317.

Segala, H. S., (2010). Konsep dan makna pembelajaran. Bandung: Alfabeta.

Silver, E. A. (1997). Fostering creativity through instruction rich in mathematical problem solving and problem posing. International Reviews on Mathematical Education, 29(3), 307317.

Smarabawa, I., Arnyana, I., \& Setiawan, I. (2013). Pengaruh model pembelajaran sains teknologi masyarakat terhadap pemahaman konsep biologi dan keterampilan berpikir kreatif siswa sma. e-Journal Program Pascasarjana Universitas Pendidikan Ganesha Program Studi IPA, 3(1), 1-11.

Sohibi, M., \& Siswanto, J. (2012). pengaruh pembelajaran berbasis masalah dan inkuiri terbimbing terhadap kemampuan berpikir kritis dan kreatif siswa. Jurnal Penelitian Pembelajaran Fisika, 3(2), 77-144.

Suartika, K., Arnyana, I., \& Setiawan, G. (2013). Pengaruh model pembelajaran kooperatif tipe group investigation (gi) terhadap pemahaman konsep biologi dan keterampilan berpikir kreatif siswa sma. e-Journal Program Pascasarjana Universitas Pendidikan Ganesha Program Studi IPA, 3(1), 1-12.

Sudjana (2002). Metode statistika. Bandung: Tarsito.

Trianggono, M. M., \& Yuanita, S. (2018). Karakteristik keterampilan berpikir kreatif dalam pemecahan masalah fisika berdasarkan gender. Jurnal Pendidikan Fisika dan Keilmuan (JPFK), 4(2), 98-106.

Winarti, T., \& Nurhayati, S., (2014). Pembelajaran praktikum berorientasi proyek untuk meningkatkan keterampilan proses sains dan pemahaman konsep. Jurnal Inovasi Pendidikan Kimia, 8(2), 1409-1420.

Wechsler, S., Vendramini, C., \& Oakland,T. (2012). Thinking and creative styles: A validity study. Journal Creativity Research. 24(3), 235-242. 